\title{
Phytochemical analysis, antioxidant activity, and nephroprotective effect of the Raphanus sativus aqueous extract
}

\author{
Hassan Zrouri ${ }^{1}$, Amine Elbouzidi ${ }^{2}$, Mohamed Bouhrim ${ }^{1}$, Noureddine Bencheikh ${ }^{1}$, Loubna \\ Kharchoufa ${ }^{1}$, Sabir Ouahhoud ${ }^{1}$, Hayat Ouassou ${ }^{1}$, Soufiane El Assri ${ }^{3}$ and Mohammed Choukri ${ }^{3}$ \\ ${ }^{1}$ Laboratory of Bioresources Biotechnology Ethnopharmacology and Health, Department of Biology, Faculty of \\ Sciences, University Mohamed Ist, Oujda, Morocco \\ ${ }^{2}$ Department of Biology, Faculty of Sciences, Mohammed First University, Oujda, Morocco \\ ${ }^{3}$ Biochemistry Laboratory, Central Laboratory Service - CHU, Mohammed VI, Oujda, Morocco
}

\begin{abstract}
In Morocco, Raphanus sativus is a widespread traditional medicinal plant used to treat various kidney diseases such as nephropathy.

Objective: The present study aims to evaluate the protective effect of the $R$. sativus aqueous extract against the gentamicin-induced acute nephrotoxicity in rats.

Methods: Rats were randomly separated into four groups $(n=6 ; \hat{\sigma} / q=1)$. The control group was treated only with distilled water $(10 \mathrm{~mL} / \mathrm{kg} ; p . o)$. The gentamicin group was treated with distilled water $(10 \mathrm{~mL} / \mathrm{kg} ; p . o)$ and injected intraperitoneally by the gentamicin $(80 \mathrm{mg} / \mathrm{kg} ;$ i.p $)$. R. sativus groups were treated with the aqueous extracts of this plant at a dose of $(200$ or $400 \mathrm{mg} / \mathrm{kg}$; p.o) and injected by the gentamicin $(80 \mathrm{mg} / \mathrm{kg}$; i.p). The plasma Creatinine, Urea, Uric Acid, Albumin, Total Protein, Alanine transaminase, Aspartate transaminase, and Calcium levels were measured. The urinary creatinine, urinary Calcium, urinary volume, water intake, creatinine clearance, body weight gain, relative right kidney weight, and kidney malondialdehydes were determined.
\end{abstract}

Results: This study showed that the daily pretreatment with $R$. sativus aqueous extract at two doses of 200 and $400 \mathrm{mg} / \mathrm{kg}$, p.o prevented the rats from the gentamicin-induced nephrotoxicity. Moreover, the R. sativus aqueous extract showed a high amount of polyphenols and flavonoids and a significant antioxidant activity.

Conclusion: $R$. sativus aqueous extract, as a novel natural product, may have preventive properties against gentamicin-induced nephrotoxicity in rats. The present study describes new areas of investigation to introduce better therapeutic agents for renal disorders and dysfunction.

Keywords: Raphanus sativus; nephrotoxicity; gentamicin; rats.

\section{Introduction}

Nephrotoxicity is one of the most prevalent kidney problems among all populations, caused by many substances, such as toxic chemicals and medicines 1,2. Many environmental xenobiotics, heavy metals, drugs, and chemicals influence the kidneys function ${ }^{3,4}$.

Renal failure is quite often associated with sepsis, diabetes, and cardiovascular diseases ${ }^{5}$. Latest studies have documented that oxidative stress is highly prevalent in patients with renal disease ${ }^{6}$. Drugs are known to cause nephrotoxicity, and it exerts their toxic effects by one or more common pathogenic mechanisms. Drug-induced nephrotoxicity appears to be more frequent in some patients and particular clinical conditions ${ }^{7}$. Many antibiotics, including

*Corresponding author: Loubna Kharchoufa

Email address: l.kharchoufa@ump.ac.ma

DOI: http://dx.doi.org/10.13171/mjc02101211565lk penicillins, tetracyclines, and aminoglycosides, can adversely affect kidney function ${ }^{8-10}$.

Gentamicin (GM) is an aminoglycoside used to treat Gram-negative bacterial infections in particular infections of the abdomen and urinary tract ${ }^{11}$. However, its use is restricted because of the development of nephrotoxicity ${ }^{12}$. Nephrotoxicity has been related to a selective accumulation of gentamicin in the renal cortex ${ }^{13}$. GM causes renal morphological changes and an overall syndrome very similar in humans and experimental animals ${ }^{14}$. Although many hypotheses have been proposed and tested, the exact mechanisms of GM-induced nephrotoxicity remain unclear. It has been shown that the GM nephrotoxicity involves the renal free radical generation, reduction in antioxidant defense mechanisms, alterations include degenerative 
changes (e.g., focal necrosis and apoptosis), and an increase of monocyte/macrophages infiltration ${ }^{15,16}$. GM nephrotoxicity leads to decreased urine concentration capacity, tubular proteinuria, lysosomal enzymatic, mild glucosuria, decreased ammonium excretion, and lower glomerular filtration rate (GFR) ${ }^{7}$. Many researchers link these mechanisms to increased peroxidation of membrane lipids ${ }^{17}$, protein denaturation, and DNA damage by generating reactive oxygen species (ROS) ${ }^{4}$. Several experiments have shown that therapy using natural antioxidants reduces the nephrotoxicity of GM in rats 18,19

$R$. sativus belonging to the Cruciferae family originated in Europe and Asia; it contains many essential vegetables of economic importance. It grows in temperate climates at altitudes ranging from 190 to $1240 \mathrm{~m}^{20}$. It is commonly used in folk medicine to treat various diseases such as gall bladder trouble, diabetes, hepatitis, and gastrointestinal disorders 20,21. Furthermore, $\boldsymbol{R}$. sativus was tested for its antiurolithiatic and diuretic effect ${ }^{22,23}$. The leaves and roots of $R$. sativus were reported to possess various biological activities like antioxidants ${ }^{24}$, hepatoprotective ${ }^{25}$, antifungal ${ }^{26}$, antiurolithiatic 27, cardioprotective 28, and gastrodynic pains ${ }^{28}$. So far, limited studies exist concerning the beneficial effects of $R$. sativus against GM-induced kidney damage. Therefore, this research aimed to investigate the nephroprotective effect of $R$. sativus aqueous extract (RSAqEx) against GM-induced renal damage in rats.

\section{Experimental}

\subsection{Chemicals and reagents}

GM ampoules $(80 \mathrm{mg} / 2 \mathrm{~mL}$, IM) were purchased from the pharmacy (Cooper Pharma Company, Morocco). Alanine aminotransferase (ALT), Aspartate aminotransferase (AST), Albumin, Total Protein, Urea, plasma Calcium, plasma Creatinine, and Urine Creatinine kits were purchased from Biosystems, Spain. All other chemicals and reagents used in this study were of high quality and analytical grade.

\subsection{Plant material}

The plant has been obtained from a local market in Oujda, Morocco. The plant was taxonomically identified, and voucher specimen HUMPOM457 was deposited at the Faculty of Sciences, University Mohammed First, Oujda, Morocco.

\subsection{Aqueous extract preparation}

Plant material was prepared according to the traditional technique used by the Moroccan population. The fresh plant was ground with a blender and decoct in water. The mixture was then filtered, and the filtrate was air-dried at $40^{\circ} \mathrm{C}$ to get the extract in powder form. After that, the crude extract was stored at $4^{\circ} \mathrm{C}$ until analysis.

\subsection{Total polyphenols quantification}

The amount of the total phenols of RSAqEx was determined by the Folin-Ciocalteau method with some modifications ${ }^{29}$. Briefly, $200 \mu \mathrm{L}$ aliquots of RSAqEx $(1000 \mu \mathrm{g} / \mathrm{mL})$ were mixed with $1000 \mu \mathrm{L}$ Folin-Ciocalteu reagent and $800 \mu \mathrm{L}(75 \mathrm{~g} / \mathrm{L})$ sodium carbonate $\left(\mathrm{Na}_{2} \mathrm{CO}_{3}\right)$. The mixture was incubated for 1 hour, and the absorbance was measured at $765 \mathrm{~nm}$ against methanol as blank. A standard curve was plotted using gallic acid as a standard. For the preparation of calibration curve, methanolic gallic acid solutions $(0.78 ; 1.56 ; 3.12 ; 6.25 ; 12.5 ; 25$; and $50 \mu \mathrm{g} / \mathrm{mL}$ ) were used. All samples were performed in triplicate. Data for the total phenol amount was presented as mg gallic acid equivalents (GAE) per mg dry matter (DM).

\subsection{Flavonoids quantification}

The total flavonoids were assessed according to the method described by Kim et al. (2003), with some modifications ${ }^{30}$. In brief, $200 \mu \mathrm{L}$ of RSAqEx (1000 $\mu \mathrm{g} / \mathrm{mL}), 1000 \mu \mathrm{L}$ distilled water, and $50 \mu \mathrm{L}$ of $\mathrm{NaNO}_{2}(5 \%)$ were mixed. After $6 \mathrm{~min}, 120 \mu \mathrm{L}$ of $\mathrm{AlCl} 3(10 \%)$ was added, followed by $5 \mathrm{~min}$ of incubation. Then, $400 \mu \mathrm{L}$ of $\mathrm{NaOH}(1 \mathrm{M})$ and $230 \mu \mathrm{L}$ of distilled water were added to the mixture. The calibration curve was made using quercetin standard solution with different concentrations $(1.56 ; 3.12$; $6.25 ; 12.5 ; 25 ; 50$ and $100 \mu \mathrm{g} / \mathrm{mL})$. The absorbance was measured at $510 \mathrm{~nm}$ using methanol as blank. All trials were performed in triplicate. The data for the concentration of total flavonoids was expressed as quercetin equivalents (QE) per mg dry matter (DM).

\subsection{Antioxidant assessment}

The 2,2-diphenyl-1-picryl-hydrazyl (DPPH) scavenging activity was measured according to the method described by Bouhrim et al. (2020) ${ }^{31}$, with some modifications. Briefly, $2.5 \mathrm{~mL}$ of methanolic solution of the free radical DPPH $(4 \%)$ was added to $0.1 \mathrm{~mL}$ of increased concentrations of RSAqEx $(0.62 ; 1.25 ; 5 ; 10 ; 20 ; 40 ; 80$ and $120 \mu \mathrm{g} / \mathrm{mL})$. The reaction mixture was incubated for $30 \mathrm{~min}$ in obscurity at room temperature, and the absorbance was measured at $517 \mathrm{~nm}$. Ascorbic acid was used as a standard reference. Methanol was used as a negative control. Redundant testing was performed three times with each sample $(n=3)$. The scavenging activity of the samples was calculated according to the following formula:

DPPH scavenging effect $\left.(\%)=\left[1-\left(A b s_{0}-A b s_{1}\right) / A b s_{0}\right)\right]$ $\times 100$

Abs0 is the absorbance of the control reaction, and Abs1 is the absorbance of all of the extract samples and standard.

The antioxidant activity is expressed as $\mathrm{IC}_{50}$ values ( $\mu \mathrm{g} / \mathrm{mL}$ of $R$. sativus). 


\subsection{Animals}

Twenty-eight Wistar rats $(\mathrm{M} / \mathrm{F}=1)$ weighing between 170 and $280 \mathrm{~g}$ and twenty-four Swiss albino mice weighing between 20 and $30 \mathrm{~g}$ were obtained from the animal house, Faculty of science, University Mohammed First, Oujda (Morocco). Animals were acclimatized for 15 days before the treatment and housed 6 per cage with food freely available and water ad libitum and maintained under a 12-h light/dark cycle (light on 07:30 - 19:30 h) and a constant temperature $\left(23 \pm 1^{\circ} \mathrm{C}\right)$.

\subsection{Acute toxicity study of $R$. sativus extract in mice}

The single-dose acute oral toxicity study was evaluated following the recommendations by OECD Guidelines (425) ${ }^{32}$. Acute toxicity test was carried out in healthy Swiss albino mice, weighing $20-28 \mathrm{~g}$ each, using a single dose, administered by oral gavage. All animals have fasted overnight, with water ad libitum. The animals were randomly divided into 4 experimental groups. Each group of 6 mice $(M / F=1)$ received, respectively, a single oral dose of 1000,3000 , or $5000 \mathrm{mg} / \mathrm{kg}$ body weight of RSAqEx, while the control group was treated with distilled water. The general behavior of mice and signs of toxicity were observed continuously for $1 \mathrm{~h}$ after the oral treatment, and then intermittently for $4 \mathrm{~h}$ and after that throughout $24 \mathrm{~h}^{33}$. The mice were further observed once a day up to 14 days following behavioral changes and toxicity and/or death signs. During this study, the mice's body weight was measured and recorded on days 1, 7, and 14. At the end of the $14^{\text {th }}$ day, the Median Lethal Dose $\left(\mathrm{LD}_{50}\right)$ was calculated according to MILLER and TRAINER $(1944)^{34}$.

\subsection{Experimental procedure}

All experiments were executed following the internationally accepted Guide for the Care and Use of Laboratory Animals, published by the US National Institutes of Health (NIH publication no. $85-23$, revised in 1985). The animals were divided into four groups, with each group consisting of six rats. Group 1; received vehicle (distilled water; p.o) for 14 days consecutively (control group). Group 2; received GM ( $80 \mathrm{mg} / \mathrm{kg}$; i.p) intraperitoneally for 14 days consecutively (gentamicin group). Groups 3 and 4 ; received GM ( $80 \mathrm{mg} / \mathrm{kg}$; i.p) and RSAqEx with doses of 200 and $400 \mathrm{mg} / \mathrm{kg}$ simultaneously; p.o administered orally for 14 days.

\subsection{Biochemical parameters}

Several biochemical parameters have been measured in urine and plasma: albumin by the Bromocresol Green method ${ }^{35}$, Calcium by the NM-BAPTA method ${ }^{36}$, urea by the enzymatic process ${ }^{37}$, creatinine by Jaffe method ${ }^{38}$, AST and ALT by IFCC method without pyridoxal-5-phosphate ${ }^{39}$, and protein by Biuret method ${ }^{40}$, Uric acid by the enzymatic colorimetric method ${ }^{41}$. All tests were performed with the COBAS INTEGRA® 400-Plus analyzer.

\subsection{Determination of creatinine clearance}

Glomerular filtration was assessed by creatinine clearance relying on serum and urinary creatinine levels, with values expressed in $\mathrm{mL} / \mathrm{min}$, calculated using the following formula:

Creatinine Clearance $(\mathrm{mL} / \mathrm{min})=$ Urine creatinine/ Serum creatinine

Urine flow was computed dividing 24 hours of urine volume by 1,440 , which corresponding to the number of minutes in 24 hours $(60 \mathrm{~min} \times 24 \mathrm{~h}=$ 1,440):

Urine flow $(\mathrm{mL} / \mathrm{min})=$ value of urine volume (24h)/1,440.

\subsection{Relative kidney weight}

On the 14th day of the experiment, the fasting rats and the live body weight ( $g$ ) were recorded on the 15 th day before euthanasia. The kidneys were separated and weighed (g) (absolute renal weight) against every animal's body mass.

Relative kidney weight $(\mathrm{g})=$ (Absolute kidney weight $(\mathrm{g})$ /Bodyweight of the rat on sacrifice day (g)) $\times 100$

\subsection{Determination of MDA}

Lipid peroxidation was evaluated by the TBARS assay using Ohkawa's method ${ }^{42}$. Kidneys were cutout, weighed, and homogenized. $0.5 \mathrm{~mL}$ of this homogenate was added to $0.5 \mathrm{~mL}$ of trichloroacetic acid $(30 \%)$ and then centrifuged for 10 minutes $(3500 \mathrm{rpm})$ at $4^{\circ} \mathrm{C}$. Then, $1 \mathrm{~mL}$ of the supernatant obtained after centrifugation was homogenized with $1 \mathrm{~mL}$ of thiobarbituric acid $(0.67 \%)$ and placed in boiled water at $100^{\circ} \mathrm{C}$ for 10 minutes and then immersed in ice to stop the reaction. The absorbance has been read at $532 \mathrm{~nm}$ using a spectrophotometer. Results were expressed in nmoles of MDA kidney produced per $\mathrm{mg}$ of tissue at $37^{\circ} \mathrm{C}$, using the molar above extinction coefficient:

\section{$1.56 \times 105 \mathrm{M}^{-1} . \mathrm{cm}^{-1}$}

\subsection{Statistical analysis}

Data expressions were presented as means \pm Standard Error of Measurement and were analyzed statistically by ANOVA (One-way-analysis of variance with Tukey post hoc test). $p<0.05$, $p<0.01$ and $p<0.001$ were considered statistically to be significant.

\section{Results and Discussion}

\subsection{Total phenols and flavonoids quantities}

The determination of the total polyphenols and flavonoids in RSAqEx was studied using the FolinCiocalteu and aluminum trichloride methods. The results showed that the complete phenol content of 
RSAqEx was $320.20 \pm 39.08 \mu \mathrm{gEAG} / \mathrm{mg} \mathrm{DM}$ and the flavonoid content was $114.29 \pm 4.79 \mu \mathrm{gEQ} / \mathrm{mg}$ DM (Table 1). These results were consistent with data from Goyeneche et al. (2015), which showed that the total polyphenol and flavonoid contents of $R$. sativus methanolic extract were $3.41 \pm 0.06$ $\mu \mathrm{gEAG} / \mathrm{mg}$ and $2.67 \pm 0.06 \mathrm{mg} \quad \mathrm{EQ} / \mathrm{mg}$ respectively ${ }^{43}$.

Table 1. Polyphenols and flavonoids contents of RSAqEx.

\begin{tabular}{|c|c|c|}
\hline & Total polyphenols (mg EAG/mg DM) & Flavonoids (mg EQ/mg DM) \\
\hline RSAqEx & $320.20 \pm 39.08$ & $114.29 \pm 4.79$ \\
\hline
\end{tabular}

\subsection{Antioxidant activity}

Figure 1 shows the RSAqEx (A) antioxidant capacity and ascorbic acid (B). The results revealed a moderate free radical scavenging capacity of RSAqEx with an $\mathrm{IC}_{50}$ equal to $30.04 \pm 0.07 \mu \mathrm{g} / \mathrm{mL}$, which is still lower compared to the ascorbic acid $\left(\mathrm{IC}_{50}=3.36 \pm 0.09 \mu \mathrm{g} / \mathrm{ml}\right)$. However, the methanolic extract of $R$. sativus showed a significant ferric reducing ability, a moderate metal chelating activity, and a strong radical scavenging activity ${ }^{44,45}$. The polyphenols and flavonoids found in the $R$. sativus aqueous extract could be responsible for this antioxidant activity.
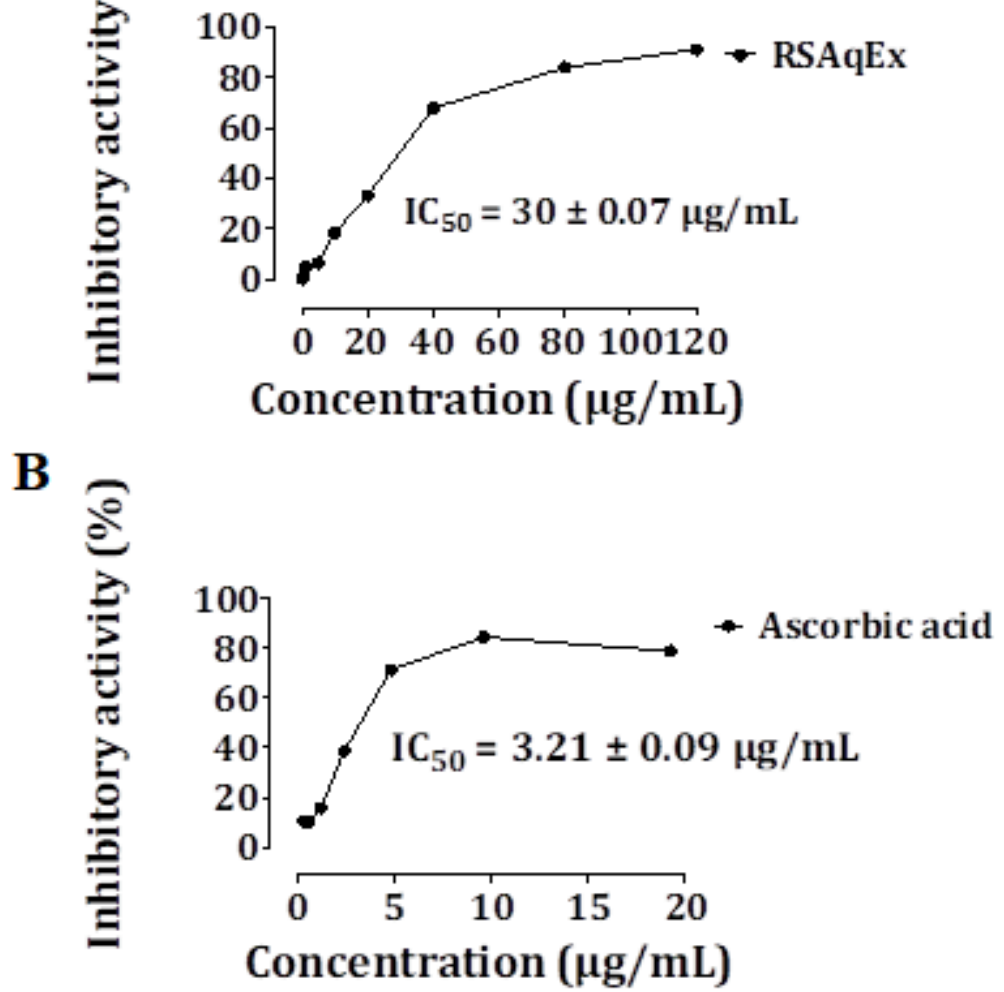

Figure 1. DPPH Free radical scavenging activity of RSAqEx (A) and ascorbic acid (B)

\subsection{Acute toxicity}

In the sighting study, the animals were monitored for 14 consecutive days following single oral administration of RSAqEx at 1000, 3000, and $5000 \mathrm{mg} / \mathrm{kg}$, and no deaths were observed. The animals did not show any symptoms of toxicity during the period of study. The animals' body weight was not significantly different between days 1,7 , and 14 (data are not shown). Moreover, the $\mathrm{LD}_{50}$ values for the oral administration of RSAqEx were greater than $5000 \mathrm{mg} / \mathrm{kg}$. According to Hodge and Sterner's (2005) classification, the tested RSAqEx falls in the fifth class (substance with $\mathrm{LD}_{50}$ higher than 5000 $\mathrm{mg} / \mathrm{kg}$ body weight) and is considered practically non-toxic ${ }^{46}$.

\subsection{Effect of RSAqEx on the water intake and urine volume}

In this study, the effect of RSAqEx on water intake and urinary volume for the rats exposed to GM was evaluated (Figure 2). No significant increase in the water intake and a significant $(\mathrm{p} \leq 0.05)$ increase in the urinary volume were observed in the rats exposed to GM than the control group. However, the administration of RSAqEx at doses of 200 and $400 \mathrm{mg} / \mathrm{Kg}$ concomitantly with GM produced a no 
significant decrease in water intake and a substantial decrease of urinary volume in the highest dose. This could be explained by the fact that GM accumulates in the renal tissue, leads to the loss of proximal tubular cells and Henle's loop to reabsorb water, which causes dehydration and increased urinary volume. Therefore an increase in water intake is necessary for compensation ${ }^{47}$.
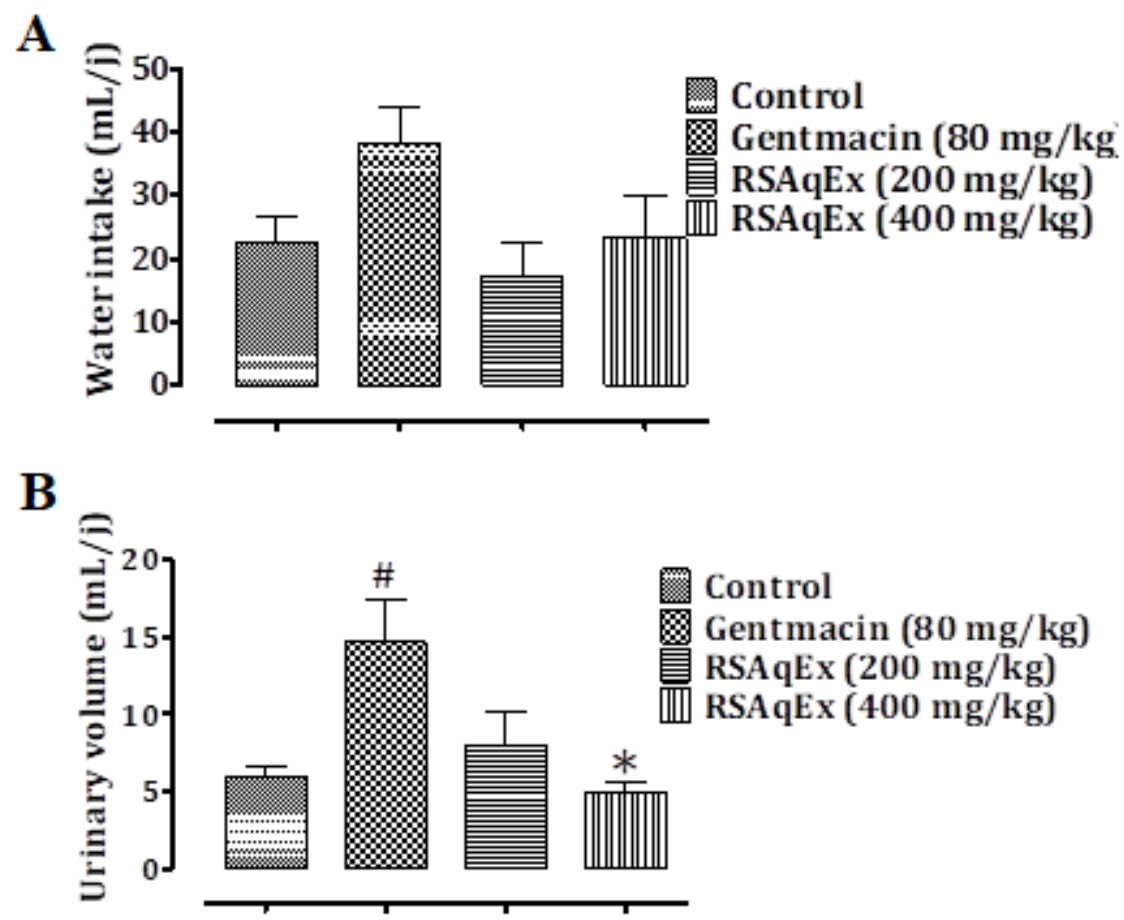

Figure 2. Effect of Raphanus sativus aqueous extract on water intake (A) and urinary volume (B) in GM exposed rats. Data are mean $\pm \mathrm{SEM}, \mathrm{n}=6$. $\# \mathrm{P} \leq 0.05$ versus the control group. ${ }^{*} \mathrm{P}<0.05$ versus GM group

3.5. Effect of RSAqEx on variation in relative right kidney weight and body weight gain The effect of RSAqEx on weight gain and relative kidney weight in GM-poisoned rats was presented in Figure 3. Daily intraperitoneal shot of the rats by the GM $(80 \mathrm{mg} / \mathrm{kg}$; i.p), produced a significant decrease $(\mathrm{p}<0.05)$ in body weight gain and increase $(\mathrm{p}<0.05)$ in relative kidney weight, compared to normal control rats. However, the daily pretreatment of the rats by the RSAqEx at doses 200 and $400 \mathrm{mg} / \mathrm{Kg}, 3$ hours before the injection of the GM, was induced a no-significant increase in body weight gain and a no-significant diminish in the relative weight of the kidneys, compared to the rats exposed only to GM (80 mg/kg; i.p). These results confirm the results of other work already published ${ }^{47,48}$. This could be due to the GM's accumulation in the kidneys, resulting in swelling of the kidneys and reduced dietary intake, thus body weight due to kidney injury ${ }^{47}$. Besides, GM's accumulation in the kidney tissue leads to the loss of tubular cells to reabsorb the water, which causes dehydration and, therefore, loss of body weight ${ }^{47}$. After treatment with GM, inflammation and edema may be responsible for increasing his kidneys' relative weight indices ${ }^{49}$. Therefore, our extract's effect on the kidneys' relative weight may be due to our plant's anti-inflammatory impact.

\subsection{Effect of RSAqEx on the plasma and urinary Calcium}

In the present study, the daily intraperitoneal injection of GM $(80 \mathrm{mg} / \mathrm{kg}$; i.p) in the experimental rats caused a significant increase $(\mathrm{p}<0.05)$ in the plasma level of Calcium and a decrease in the level of urinary Calcium in a not significant manner, compared to the rats in the control group (Figure 4). On the other hand, administering RSAqEx to rats exposed to GM resulted in a reduction in plasma calcium concentration and an increase in calcium concentration in the urine. The reversal of GM's deleterious effect on the plasma calcium concentration was significant $(\mathrm{p}<0.01)$ at the dose of $400 \mathrm{mg} / \mathrm{kg}$ and was not significant for urinary calcium concentration. This effect can be explained by gentamicin's action on the membrane supports of both the brush border and the basolateral membranes leading to electrolyte abnormalities ${ }^{47}$. Since the nephrotoxicity caused by reactive oxygen species generated by gentamicin injection, it appeared that the nephroprotective effect of RSAqEx on gentamicin-induced renal damage might be due to the antioxidant activity of RSAqEx. 
A

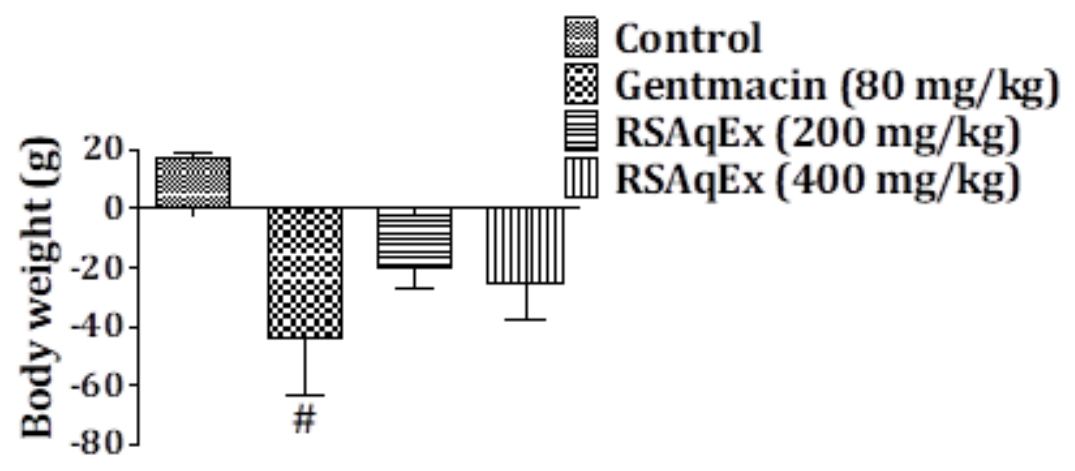

B

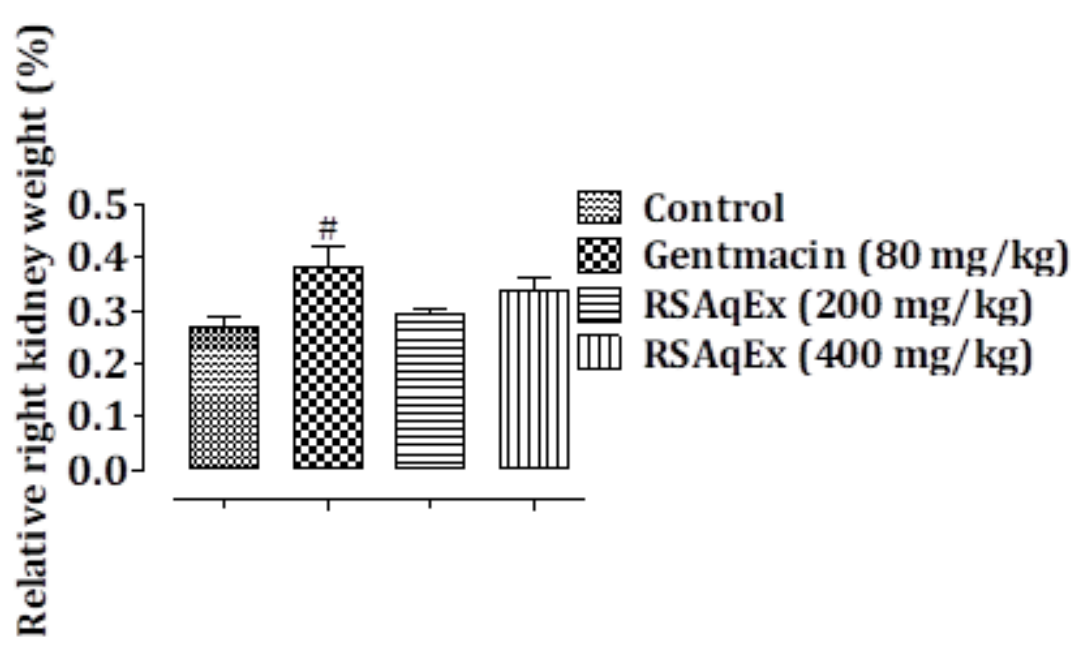

Figure 3. Effect of the RSAqEx on variation in body weight gain (A) and relative kidney weight (B) in GM exposed rats. Data are mean $\pm \mathrm{SEM}, \mathrm{n}=6$. \# $\mathrm{P} \leq 0.05$ versus the control group. ${ }^{*} \mathrm{P}<0.05$ versus $\mathrm{GM}$ group

A

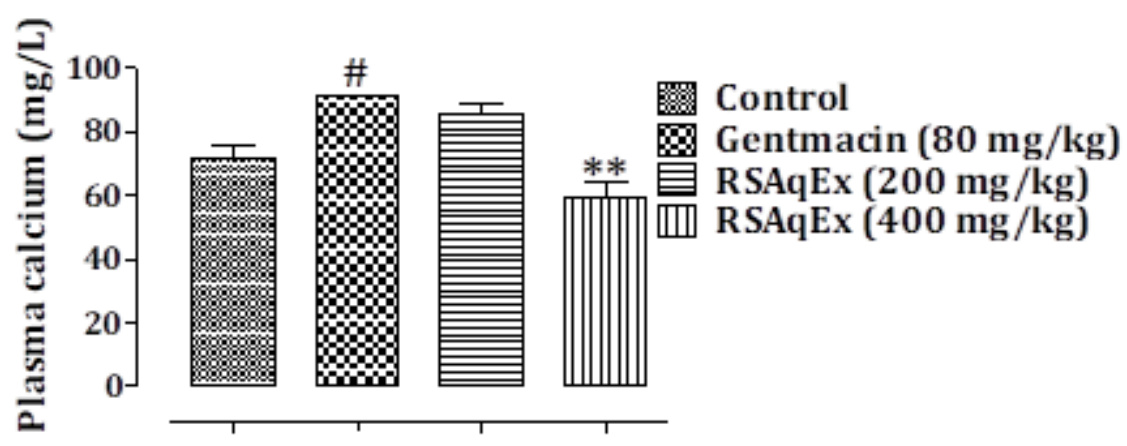

B

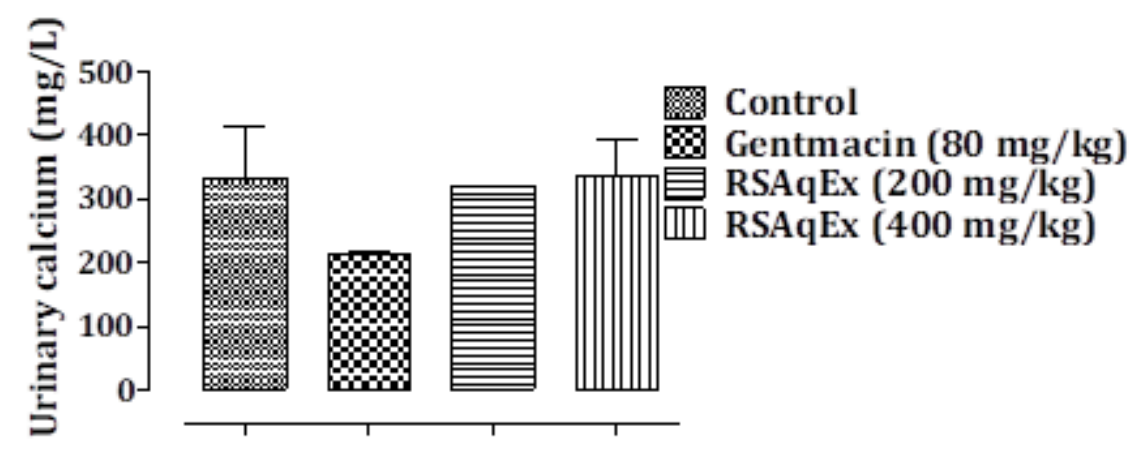

Figure 4. Effect of the RSAqEx on the plasma (A) and urinary (B) calcium in GM exposed rats. Data are mean \pm $\mathrm{SEM}, \mathrm{n}=6$. $\# \mathrm{P} \leq 0.05$ versus a control group. $* * \mathrm{P}<0.01$ versus $\mathrm{GM}$ group 


\subsection{Effect of RSAqEx on plasma urea, plasma creatinine, urine creatinine, and creatinine clearance}

The effect of various doses of RSAqEx on plasma urea in GM intoxicated rats was showed in Figure 5. Results showed that intraperitoneal injection of GM $(80 \mathrm{mg} / \mathrm{kg}$; i.p) to the rats increased urea plasma levels significantly compared with the control group. These results were consisted of the results of Erdem

A

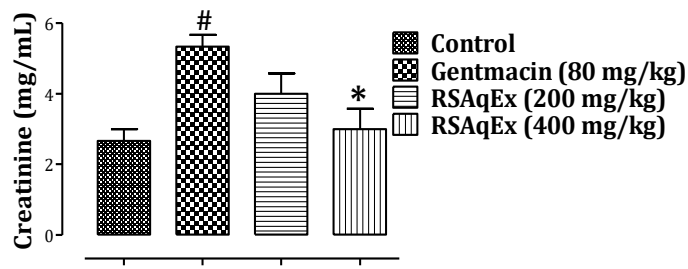

C

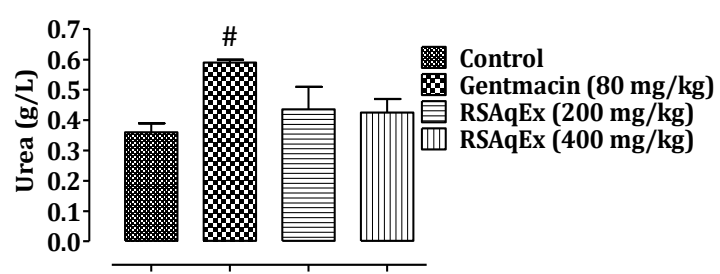

et al. (2000) ${ }^{50}$, indicating altered glomeruli and tubular functions in the rats. Furthermore, there was no significant decrease in plasma levels of urea in rats treated with RSAqEx at doses 200 and 400 $\mathrm{mg} / \mathrm{kg}$ compared with the GM group. The effect of RSAqEx could be due to the antioxidant properties of its polyphenols and flavonoids compounds ${ }^{50}$. And maybe using a high dose of RSAqEx can produce significant results.

\section{B}

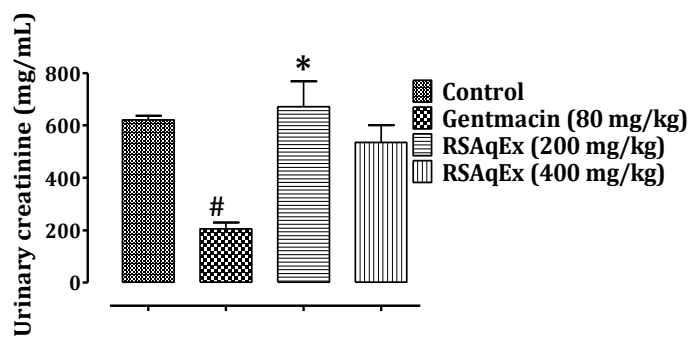

D

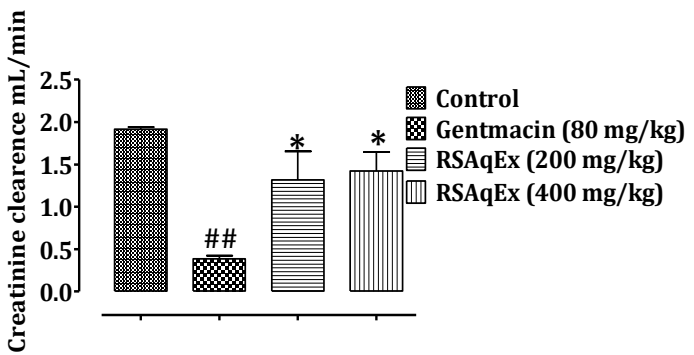

Figure 5. The effect of RSAqEx at 200 and $400 \mathrm{mg} / \mathrm{kg}$ on the plasma creatinine (A) and urinary creatinine (B) plasma urea (C) and creatinine clearance (D) in GM intoxicated rats. The results were expressed by mean \pm SEM $(\mathrm{n}=6)$. \# $\mathrm{P} \leq 0.05, \# \# \mathrm{P} \leq 0.05$ versus a control group $* \mathrm{P}<0.05$ versus $\mathrm{GM}$ group

As shown in Figure 5, the effect of RSAqEx on serum and urine creatinine levels for all treated groups was evaluated. The marked increase in serum and urinary creatinine has been considered as a significant functional impairment of the kidneys in GM-induced renal failure ${ }^{51}$. A significant increase in serum creatinine $(\mathrm{p}<0.05)$ and a significant decrease $(p<0.05)$ in urinary creatinine were observed in the rats exposed to GM ( $80 \mathrm{mg} / \mathrm{kg}$; i.p) compared to the animals in the normal controlled group. However, a significant decrease in the serum creatinine level $(\mathrm{p}<0.05)$ at the dose of $400 \mathrm{mg} / \mathrm{Kg}$ and a significant increase $(p<0.05)$ in the urinary creatinine level at dose $200 \mathrm{mg} / \mathrm{Kg}$ were observed in rats pretreated with RSAqEx, compared to the GM group. The dose of $400 \mathrm{mg} / \mathrm{Kg}$ did not induce a significant increase in the urinary creatinine level; this data may be produced by how the molecules interfere with each other to induce this biological effect. These results were in good agreement with the results of other previously published work ${ }^{49}$. Several studies have reported that aminoglycoside (gentamicin) is a classic antibiotic able to cause nephrotoxicity by inducing reactive oxygen species 52,53 . Natural antioxidants such as polyphenols and flavonoids are known to trap free radicals in vivo ${ }^{54}$. The characteristic phytochemical constituents in $\mathrm{R}$. sativus are flavonoids and phenolic acids. It is noteworthy to suggest that RSAqEx can ameliorate renal function in GM-intoxicated rats by neutralizing the free radicals caused by gentamicin. The effect of RSAqEx on creatinine clearance was evaluated in all rats in the study groups (Figure 5, D). GM caused a significant decrease $(\mathrm{p}<0.01)$ in creatinine clearance. Administration of RSAqEx at doses 200 and 400 $\mathrm{mg} / \mathrm{kg}$ significantly $(\mathrm{p}<0.05)$ decreased creatinine clearance in the rats exposed to GM $(80 \mathrm{mg} / \mathrm{kg}$; i.p). These results were concordant with those found by Hosaka et al. (2004) and Govindappa et al. (2019) ${ }^{47,55}$.Effect of RSAqEx of the plasma AST and ALT.

The effect of various doses of RSAqEx on ALT (A) enzymatic activity (A) and AST (B) in GM intoxicated rats was shown in Figure 6. Data showed that GM $(80 \mathrm{mg} / \mathrm{kg}$; i.p) did not significantly influence ALT and AST's enzymatic activity than the control group. Elevated serum ALT activities, AST after treatment with gentamicin in agreement with the study of sally et al., $2016^{56}$. They were indicating hepatic damage to rat hepatocytes ${ }^{57}$. 
Besides, there was no significant effect on ALT and AST's enzymatic activity in rats treated with RSAqEx at 200 and $400 \mathrm{mg} / \mathrm{kg}$ compared with the
GM group. The decreased ALT activity and AST in rats treated with RSAqEx might be due to bioactive molecules with antioxidant properties.

$\mathbf{A}$

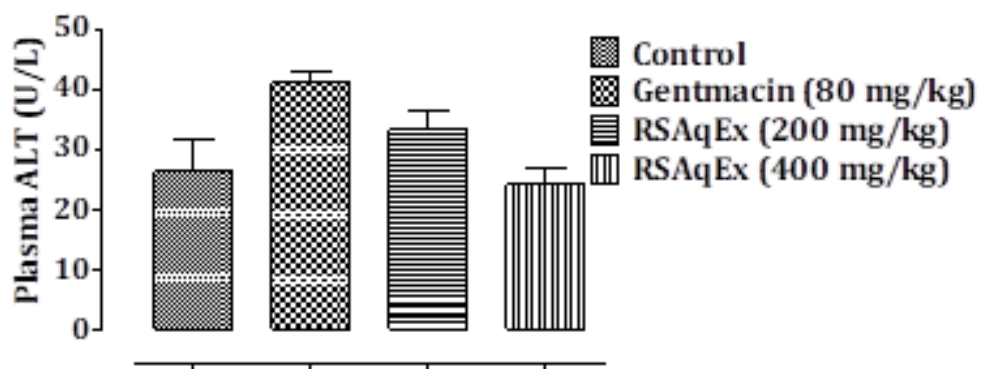

B

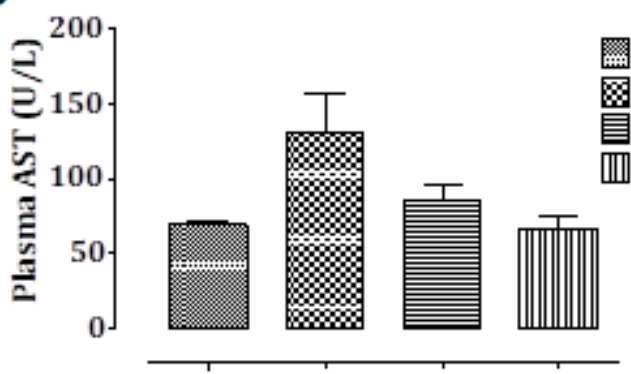

Control

Gentmacin $(80 \mathrm{mg} / \mathrm{kg})$

R. sativus (200 mg/kg)

R. sativus (400 mg/kg)

Figure 6. The effect of RSAqEx at 200 and $400 \mathrm{mg} / \mathrm{kg}$ on plasma ALT (A) and AST (B) in GM intoxicated rats. The results were expressed by mean $\pm \operatorname{SEM}(n=6)$

3.8. Effect of RSAqEx on the plasma albumin, total protein, and lipid peroxidation

The levels of plasma total proteins and albumin in control, GM, and RSAqEx treated animals were showed in Figure 7. The treatment of rats with GM induced a significant increase in plasma total proteins and albumin levels $(\mathrm{p}<0.05$ and $\mathrm{p}<0.01$, respectively). However, gentamicin treatment causes this variation in total protein and albumin, useful liver function markers, might be depressed due to defective protein synthesis ${ }^{58}$. These findings were in good agreement with the results of other previously published work ${ }^{47}$. The administration of RSAqEx extract at $400 \mathrm{mg} / \mathrm{kg}$ decreased significantly the total plasma proteins and albumin levels $(\mathrm{p}<0.01$ and $\mathrm{p}<0.001$, respectively) compared to the GM group. The RSAqEx at $200 \mathrm{mg} / \mathrm{kg}$ was produced a significant decrease in plasma albumin levels $(p<0.05)$. Still, there was no significant effect on the total plasma proteins compared to the GM group. The enhancing effect on plasma total protein and albumin might due to the bioactive compounds of RSAqEx. This result suggests that these natural compounds have an overall protective effect on the hepatic and renal cells.
The kidney MDA levels in control, GM, and treated RSAqEx animals were showed in Figure 7. The injection of rats with GM induced a significant elevation in kidney MDA levels ( $p<0.01)$, The GM is assumed to be associated with the production of reactive oxygen species in the form of superoxide anion $\left(\mathrm{O}_{2}\right)$, hydrogen peroxide $\left(\mathrm{H}_{2} \mathrm{O}_{2}\right)$, and hydroxyl radical $(\mathrm{OH} \bullet)$ of renal cortical mitochondria, which are accompanied by an increase in lipid peroxidation ${ }^{59}$. Changes in the lipid composition of the membrane could be induced by the lipid peroxidation initiated by free radicals with a subsequent increase in MDA, one of the products of lipid peroxidation ${ }^{51}$. In this investigation, the GM's daily administration by rats was caused an increase in the lipid peroxidation, which is indicated by the elevation of renal MDA. Our results agreed with Kumar et al. (2019), who reported that the treatment with gentamicin increase renal MDA level ${ }^{47}$. Whereas a significant decrease in kidney MDA levels was observed on intoxicated rats treated with RSAqEx at 200 and $400 \mathrm{mg} / \mathrm{kg}(\mathrm{p}<0.05, \mathrm{p}<0.01$, respectively). The mechanism of this protective effect might be due to the antioxidant potential of RSAqEx that is responsible for the diminution of the oxidative damage in the renal tubular cell membrane. 
A

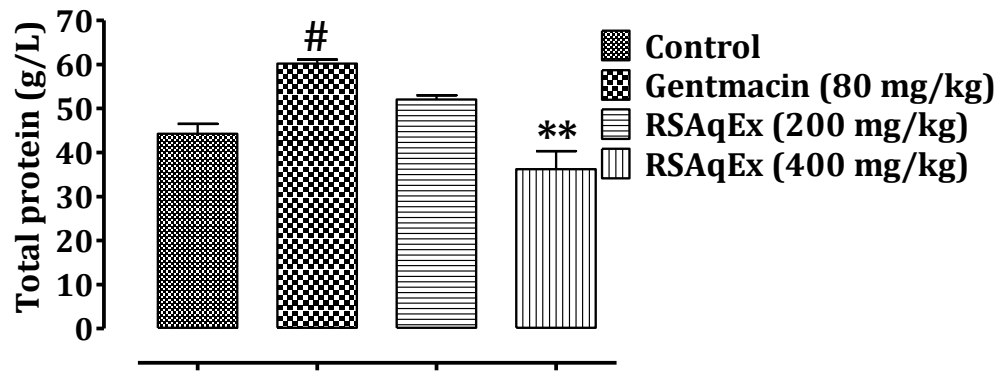

B

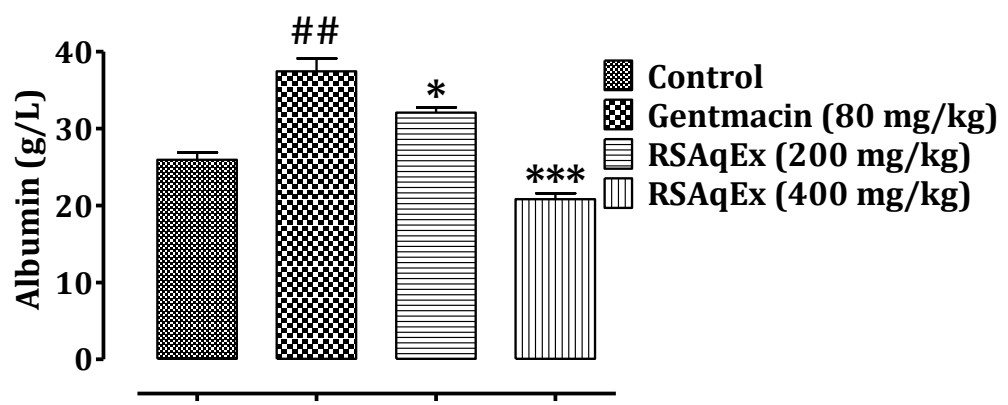

C

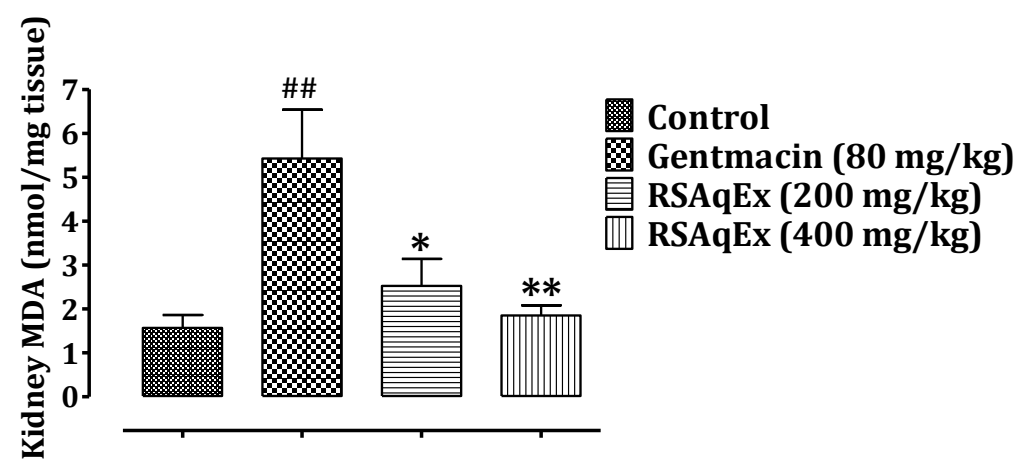

Figure 7. The effect of RSAqEx at 200 and $400 \mathrm{mg} / \mathrm{kg}$ on the total protein (A) albumin (B) and kidney levels of MDA (C) in GM intoxicated rats. The results were expressed by mean \pm SEM (n=6); \#p <0.05; \#\#p < 0.01 compared with control; *p<0, 05; **p $<0,01 ; * * * \mathrm{p}<0,001$ compared with GM group

\section{Conclusion}

In conclusion, our results showed that the oral administration of $R$. sativus exerted favorable nephroprotective activity against gentamicin-induced renal damage in rats. This effect could be due to the presence of flavonoids, polyphenols, and other bioactive compounds. Furthermore, complementary studies will be necessary for precise mechanisms involved in $R$. sativus -induced renal protection.

\section{Conflict of interest}

The authors declare that there is no conflict of interest.

\section{Acknowledgments}

This work intends to express their appreciation to Ramdaoui Karim and Badraoui Mustapha for their technical assistance.

\section{References}

1- M. Salai Bojan, R. Rajappa, D. R. K. Vijayakumar, J. Gopalan, Protective effect of Raphanus sativus on D-galactosamine induced nephrotoxicity in rats, Nutr Clin Metab, 2016, 30 , $22-28$.

2- S. J. Y, S. Nikhat, J. A. Khan, S. Zohaib, Nephroprotective concept and drugs described in Unani system of medicine : A review, 2018, 2, 36-39.

3- S. Fatima, A. N. K. Yusufi, R. Mahmood, Effect of cisplatin on renal brush border membrane enzymes and phosphate transport, Hum Exp Toxicol, 2004, 23, 547-554.

4- M. Ouédraogo, A. Lamien-Sanou, N. Ramdé, A. S. Ouédraogo, M. Ouédraogo, S. P. Zongo, O. Goumbri, P. Duez, P. I. Guissou, Protective effect of Moringa oleifera leaves against gentamicin-induced nephrotoxicity in rabbits, Exp Toxicol Pathol, 2013, 65, 335-339.

5- M. Bouhrim, H. Ouassou, E. Loukili, M. 
Ramdani, H. Mekhfi, A. Ziyyat, A. Legssyer, M. Aziz, M. Bnouham, Antidiabetic effect of Opuntia dillenii seed oil on streptozotocininduced diabetic rats, Asian Pac J Trop Biomed, 2019, 9, 381-388.

6- W. M. Haschek, C. G. Rousseaux, M. A. Wallig, B. Bolon, R. Ochoa, Haschek and Rousseaux's handbook of toxicologic pathology, Academic Press, 2013.

7- P. Chatterjee, A. Mukherjee, S. Nandy, Protective effects of the aqueous leaf extract of Aloe barbadensis on gentamicin and cisplatininduced nephrotoxic rats, Asian Pac J Trop Biomed, 2012, 2, S1754-S1763.

8- P. M. Tulkens, Nephrotoxicity of aminoglycoside antibiotics, Toxicol Lett, 1989, 46, 107-123.

9- H. T. LEW, S. W. FRENCH, Tetracycline nephrotoxicity and nonoliguric acute renal failure, Arch Intern Med, 1966, 118, 123-128.

10- B. M. Tune, Nephrotoxicity of beta-lactam antibiotics: mechanisms and strategies for prevention, Pediatr Nephrol, 1997, 11, 768-772.

11- J. Nagai, M. Takano, Molecular aspects of renal handling of aminoglycosides and strategies for preventing the nephrotoxicity., Drug Metab Pharmacokinet, 2004, 19, 159-170.

12- J. P. Morin, G. Viotte, A. Vandewalle, F. Van Hoof, P. Tulkens, J. P. Fillastre, Gentamicininduced nephrotoxicity: A cell biology approach, Kidney Int, 1980, 18, 583-590.

13- A. G. G. Coutinho, S. M. P. Biscaia, R. Fernandez, A. L. Tararthuch, The aminoglycoside antibiotic gentamicin is able to alter metabolic activity and morphology of MDCK-C11 cells: A cell model of intercalated cells, Brazilian J Med Biol Res, 2018, 51, 1-7.

14- F. C. Luft, M. N. Yum, P. D. Walker, S. A. Kleit, Gentamicin gradient patterns and morphological changes in human kidneys, Nephron, 1977, 18, 167-174.

15- P. Balakumar, A. Rohilla, A. Thangathirupathi, Gentamicin-induced nephrotoxicity: Do we have a promising therapeutic approach to blunt it?, Pharmacol Res, 2010, 62, 179-186.

16- J. M. Lopez-Novoa, Y. Quiros, L. Vicente, A. I. Morales, F. J. Lopez-Hernandez, New insights into the mechanism of aminoglycoside nephrotoxicity: An integrative point of view, Kidney Int, 2011, 79, 33-45.

17- C. Yanagida, K. Ito, I. Komiya, T. Horie, Protective effect of fosfomycin on gentamicininduced lipid peroxidation of rat renal tissue, Chem Biol Interact, 2004, 148, 139-147.

18- M. Tavafi, H. Ahmadvand, P. Toolabi, Inhibitory effect of olive leaf extract on gentamicin-induced nephrotoxicity in rats, 2012.

19- C. Kang, H. Lee, D. Y. Hah, J. H. Heo, C. H. Kim, E. Kim, J. S. Kim, Protective effects of Houttuynia cordata Thunb. on gentamicininduced oxidative stress and nephrotoxicity in rats, Toxicol Res, 2013, 29, 61-67.

20- R. M. P. Gutiérrez, R. L. Perez, Raphanus sativus (Radish): their chemistry and biology., Scientific WorldJournal, 2004, 4, 811-837.

21- A. R. S. Devraj Shetty, Rajesh Kamath, Pratibha Bhat, Karunakar Hegde*, ANTHELMINTIC ACTIVITY OF ROOT EXTRACT OF RAPHA?US SATIVUS, Pharmacologyonline, 2011, 1, 675-679.

22- K. Agarwal, R. Varma, Ethnobotanical study of antilithic plants of Bhopal district, $J$ Ethnopharmacol, 2015, 174, 17-24.

23- J. P. B. and M. J. Rahul Deo Yadav, S. K. Jain, Shashi Alok, Alok Mahor, Herbal Plants Used in the Treatment of Urolithiasis : a Review, Int J Pharm Res Dev, 2013, 5, 66-70.

24- S. S. Beevi, L. N. Mangamoori, B. B. Gowda, Polyphenolics profile and antioxidant properties of Raphanus sativus L., Nat Prod Res, 2012, 26, 557-563.

25- M. Ahn, R. K. Koh, G. O. Kim, T. Shin, Aqueous extract of purple Bordeaux radish, Raphanus sativus L. ameliorates ethanol-induced gastric injury in rats, Orient Pharm Exp Med, 2013, 13, 247-252.

26- F. R. G. Terras, H. M. E. Schoofs, M. F. C. De Bolle, F. Van Leuven, S. B. Rees, J. Vanderleyden, B. P. A. Cammue, W. F. Broekaert, Analysis of two novel classes of plant antifungal proteins from radish (Raphanus sativus L.) seeds, J Biol Chem, 1992, 267, 15301-15309.

27- R. Vargas S., R. M. Perez G., S. Perez G., M. A. Zavala S., C. Perez G., Antiurolithiatic activity of Raphanus sativus aqueous extract on rats, $J$ Ethnopharmacol, 1999, 68, 335-338.

28- M. N. Ghayur, A. H. Gilani, Gastrointestinal stimulatory and uterotonic activities of dietary radish leaves extract are mediated through multiple pathways, Phyther Res, 2005, 19, 750755.

29- O. Folin, V. Ciocalteau, Tyrosine and Tryptophane in Proteins, J Biol Chem, 1927, 73, 627-648.

30- D.-O. Kim, O. K. Chun, Y. J. Kim, H.-Y. Moon, C. Y. Lee, Quantification of polyphenolics and their antioxidant capacity in fresh plums, J Agric Food Chem, 2003, 51, 6509-6515.

31- M. Bouhrim, N. E. Daoudi, H. Ouassou, A. Benoutman, E. H. Loukili, A. Ziyyat, H. Mekhfi, A. Legssyer, M. Aziz, M. Bnouham, Phenolic Content and Antioxidant, Antihyperlipidemic, and Antidiabetogenic Effects of Opuntia dillenii Seed Oil, Sci World J, 2020, 2020.

32- O. OECD, Guideline for the Testing of Chemicals. Acute Oral Toxicity e Acute Toxic Class Method: Test No-423, Organ Econ Coop Dev, 2001.

33- H. A. A. Twaij, A. Kery, N. K. Al-Khazraji, Some pharmacological, toxicological and phytochemical investigations on Centaurea phyllocephala, J Ethnopharmacol, 1983, 9, 299314.

34- T. M. M. LC, Estimation of LD50 and its error by means of log-probit graph paper, Proc Soc 
Exp Biol Med, 1944, 57, 261.

35- B. T. Doumas, W. A. Watson, H. G. Biggs, Albumin standards and the measurement of serum albumin with bromcresol green, Clin Chim acta, 1971, 31, 87-96.

36- C. Bourguignon, A. M. Dupuy, T. Coste, F. Michel, J. P. Cristol, Evaluation of NM-BAPTA method for plasma total calcium measurement on Cobas 8000®, Clin Biochem, 2014, 47, 636-639.

37- H. Talke, G. E. Schubert, Enzymatic urea determination in the blood and serum in the Warburg optical test, Klin Wochenschr, 1965, 43, 174.

38- R. J. Henry, Clinical chemistry, principles and technics, 1964.

39- A. Karmen, F. Wróblewski, J. S. LaDue, Transaminase activity in human blood, J Clin Invest, 1955, 34, 126-133.

40- A. G. Gornall, C. J. Bardawill, M. M. David, Determination of serum proteins by means of the biuret reaction, J Biol Chem, 1949, 177, 751766.

41- P. et al Fossati, Use of 3,5-dichloro-2hydroxybenzenesulfonic acid/4-aminophenazone chromogenic system in direct enzymic assay of uric acid in serum and urine, Clin Chem, $\mathbf{1 8 8 0}$, 26, 227-231.

42- H. Ohkawa, N. Ohishi, K. Yagi, Assay for lipid peroxides in animal tissues by thiobarbituric acid reaction, Anal Biochem, 1979, 95, 351-358.

43- R. Goyeneche, S. Roura, A. Ponce, A. VegaGálvez, I. Quispe-Fuentes, E. Uribe, K. Di Scala, Chemical characterization and antioxidant capacity of red radish (Raphanus sativus L.) leaves and roots, J Funct Foods, 2015, 16, 256264.

44- S. S. Beevi, L. N. Mangamoori, B. B. Gowda, Polyphenolics profile and antioxidant properties of Raphanus sativus L., Nat Prod Res, 2012, 26, 557-563.

45- K. S. Jamuna, C. K. Ramesh, R. Mahmood, M. Pallavi, A. R. S. J, Effect of different extraction methods on total phenolic content and antioxidant activities of Raphanus sativus, Int J Bioassays, 2015, 4, 4653-4657.

46- I. V Berezovskaya, Classification of substances with respect to acute toxicity for parenteral administration, Pharm Chem J, 2003, 37, 139141.

47- P. K. Govindappa, V. Gautam, S. M. Tripathi, Y. P. Sahni, H. L. S. Raghavendra, Effect of Withania somnifera on gentamicin induced renal lesions in rats, Brazilian J Pharmacogn, 2019, 29, 234-240.

48- M. Tavafi, Protection of renal tubules against gentamicin induced nephrotoxicity., J Ren Inj
Prev, 2013, 2, 5-6.

49- D. H. El-Kashef, A. E. El-Kenawi, M. A. Rahim, G. M. Suddek, H. A. Salem, Agmatine improves renal function in gentamicin-induced nephrotoxicity in rats, Can J Physiol Pharmacol, 2016, 94, 278-286.

50- A. Erdem, N. Ü. Gündoğan, A. Usubütün, K. Kilinç, Ş. R. Erdem, A. Kara, A. Bozkurt, The protective effect of taurine against gentamicininduced acute tubular necrosis in rats, Nephrol Dial Transplant, 2000, 15, 1175-1182.

51- S. Kalayarasan, P. N. Prabhu, N. Sriram, R. Manikandan, M. Arumugam, G. Sudhandiran, Diallyl sulfide enhances antioxidants and inhibits inflammation through the activation of Nrf2 against gentamicin-induced nephrotoxicity in Wistar rats, Eur J Pharmacol, 2009, 606, 162171.

52- M. A. Perazella, Pharmacology behind common drug nephrotoxicities, Clin J Am Soc Nephrol, 2018, 13, 1897-1908.

53- P. Randjelović, S. Veljković, N. Stojiljković, D. Sokolović, I. Ilić, Gentamicin nephrotoxicity in animals: Current knowledge and future perspectives, EXCLI J, 2017, 16, 388-399.

54- S. Ravikumar, M. Gnanadesigan, Hepatoprotective and Antioxidant Properties of Rhizophora mucronata Mangrove Plant in $\mathrm{CCl} 4$ Intoxicated Rats, J Exp Clin Med, 2012, 4, 6672.

55- E. M. Hosaka, O. F. P. dos Santos, A. C. Seguro, M. de F. F. Vattimo, Effect of cyclooxygenase inhibitors on gentamicin-induced nephrotoxicity in rats, Brazilian J Med Biol Res, 2004, 37, 979985.

56- S. A. Abuelezz, N. Hendawy, S. Abdel Gawad, Alleviation of renal mitochondrial dysfunction and apoptosis underlies the protective effect of sitagliptin in gentamicin-induced nephrotoxicity, J Pharm Pharmacol, 2016, 68, 523-532.

57- M. Bouhrim, H. Ouassou, M. Choukri, H. Mekhfi, A. Ziyyat, A. Legssyer, M. Aziz, M. Bnouham, Hepatoprotective effect of Opuntia dillenii seed oil on CCl4 induced acute liver damage in rat, Asian Pac J Trop Biomed, 2018, 8, 254-260.

58- M. R. Khan, I. Badar, A. Siddiquah, Prevention of hepatorenal toxicity with Sonchus asper in gentamicin treated rats, BMC Complement Altern Med, 2011, 11, 3-11.

59- C. R. Patil, R. B. Jadhav, P. K. Singh, S. Mundada, P. R. Patil, Protective effect of oleanolic acid on gentamicin induced nephrotoxicity in rats, Phyther Res An Int J Devoted to Pharmacol Toxicol Eval Nat Prod Deriv, 2010, 24, 33-37. 